\title{
Identidade e variação semânticas do verbo SECAR no português do Brasil
}

DOI: http://dx.doi.org/10.21165/el.v48i3.2259

\author{
Márcia Romero' \\ Juliana Perez Kiihl²
}

\section{Resumo}

Resultado da pesquisa realizada por Kiihl (2016) e Romero (2016), objetiva-se mostrar neste artigo como a identidade semântica verbal se elabora na integração do verbo ao enunciado. A Teoria das Operações Predicativas e Enunciativas, referencial teórico que fundamenta o quadro analítico-metodológico do trabalho, concebe o sentido verbal como o produto de seu enunciar, o que implica ser a identidade semântica da unidade, quando fora da contextualização que lhe confere o enunciado, da ordem de um esquema operatório invariante, denominado forma esquemática. O estudo, direcionado ao verbo SECAR em PB, delimita o referido esquema por meio da análise de enunciados variados, extraídos de fontes primárias e secundárias, mostrando como ele é o responsável por organizar a variação semântica verbal.

Palavras-chave: Teoria das Operações Predicativas e Enunciativas; verbo; identidade e variação semânticas.

\footnotetext{
1 Universidade Federal de São Paulo (UNIFESP), São Paulo, São Paulo, Brasil, marcia.romero@unifesp.br; http://orcid.org/0000-0001-5204-111X

2 Universidade Federal de São Paulo (UNIFESP), São Paulo, São Paulo, Brasil, julianakiihl@hotmail.com; http://orcid.org/0000-0003-3188-1704
} 


\title{
Semantic identity and variation of the verb SECAR in Brazilian Portuguese
}

\begin{abstract}
As a result of the research conducted by Kiihl (2016) and Romero (2016), this article aims to demonstrate how the verbal semantic identity elaborates itself through the process of integrating a sentence. The Theory of Predicative and Enunciative Operations, theoretical framework that founds this research in terms of analytical methodological approach, conceives verbal meaning as a product of the act of enunciation, which is the given lexical unit's semantic identity, even when considered out of its lexical environment, from an invariant operative system named schematic form. The present study, referring to the verb SECAR in Brazilian Portuguese, delimits the scheme mentioned above through the analysis of varied sentences, extracted from primary and secondary sources, demonstrating the way it is responsible for organizing verbal semantic variance.
\end{abstract}

Keywords: Theory of Predicative and Enunciative Operations; verb; semantic identity and variation.

\section{Introdução}

Neste trabalho ${ }^{3}$, resultado das pesquisas realizadas por Kiihl (2016) e Romero (2016), vamos nos ater à análise de enunciados construídos com o verbo SECAR no português do Brasil (PB) a fim de examinar como se delineia a identidade semântica verbal no processo de integração enunciativa sob a ótica do referencial teórico por nós adotado, a saber, a Teoria das Operações Predicativas e Enunciativas (TOPE), de Antoine Culioli (CULIOLI, 1990, 1999a, 1999b).

O conceito de linguagem que permeia nossas análises é o que se refere a uma atividade significante da espécie humana que consiste não "em veicular sentido, mas em produzir e reconhecer formas enquanto traços de operações" (CULIOLI, 1990, p. 26). As formas, no caso, os enunciados, não se elaboram por meio de integração de unidades linguísticas que teriam sentidos ${ }^{4}$ independentemente deles. Daí sustentarmos um processo de construção de significação que se dá na integração da unidade a ser analisada - nesse caso, o verbo SECAR - aos enunciados. É, portanto, pelo exame minucioso do agenciamento do verbo, i.e. dos diferentes contextos verbais que ele solicita para se enunciar, que se delineiam os traços das operações de ordem linguageira que caracterizam a sua identidade semântica. Compreender e definir a identidade semântica do verbo passa, assim, pela tomada

3 Apoio FAPESP (processo 2013/07572-0). Agradecemos aos pareceristas da revista Estudos Linguísticos pelas contribuições dadas.

4 A materialidade semântica de uma dada unidade linguística não é da ordem de traços sêmicos. 
de consciência de como se dá o funcionamento enunciativo de SECAR em diferentes produções verbais.

Por meio da análise de como o verbo varia em seus empregos - variação que não está relacionada ao exame dos diferentes sentidos por ele adquiridos nos enunciados, mas ao modo como o verbo, de um lado, age sobre os contextos verbais que ele mesmo convoca ao se enunciar, de outro, se vê igualmente por eles delimitados -, verificar-se-á o que há de regular, de invariante em seu funcionamento enunciativo.

Para dar um único exemplo, consideremos o enunciado tido por prototípico do emprego deste verbo:

1. No inverno secamos muito os cabelos e, assim como a água quente faz mal, o vapor quente também faz ${ }^{5}$.

Em primeiro lugar, vale dizer que o enunciado remete a um estado primeiro de os cabelos, que é o não molhado. SECAR exprime, portanto, a volta a um estado primeiro seco, que se opõe a molhado. Em segundo lugar, que se apreende o SN os cabelos como fibras capilares nas quais a água se espalha. O verbo diz que as fibras não contêm mais líquido, em maior ou menor grau (elas tendem a se apresentar firmes, coesas, conforme o estado relativo ao secar, mais ou menos seco). Aparentemente simples, essa análise permite observar a presença de dois parâmetros: $(X)$ a água e $(Y)$ os cabelos, este último como fibras capilares nas quais a água (o líquido) se espalha; ou então, $(X)$ como o que apresenta a qualidade líquida e $(Y)$ como o que localiza $(X)$. SECAR exprime a remoção de $(X)$ localizado por $(Y)$.

Ora, vê-se a diferença em termos de representação construída se compararmos SECAR a CORTAR quando este tem igualmente por argumento os cabelos. Neste caso, se o SN os cabelos pode ser apreendido como fibras capilares, é sob a ótica da característica linear própria a fio que CORTAR o apreende: sua linearidade é interrompida, a ponto de se ter, como um estado resultante da predicação, "pedaços, partes" de cabelo (a parte cortada) ${ }^{6}$. Com SECAR, como veremos, a predicação nunca conduzirá a um estado resultante semelhante: tem-se unicamente a passagem do que não apresentava a qualidade seco ao que, agora, a apresenta. Isso explica o porquê de as representações referirem-se a oposições de natureza qualitativa seco-molhado, secocheio, seco-vigoroso, etc..

5 Os enunciados constam de Kiihl (2016) e Romero (2016). Fazem parte do corpora do projeto Léxico e enunciação: sistematização do funcionamento verbal (FAPESP 2013/07572-0).

6 Ver Assis (2014), para estudo do verbo CORTAR em PB. 
Propomo-nos, tal como no enunciado (1), a refletir sobre o que vem a ser os parâmetros $(X)$ e $(Y)$ na predicação estabelecida por SECAR em diferentes enunciados com vistas à identificação do esquema relacional constitutivo de seu semantismo e definidor de seu funcionamento enunciativo: sua forma esquemática (FE).

A FE figura na base de um modelo de identidade lexical no qual o semantismo verbal é caracterizado por um esquema operatório dinâmico e invariante. Investiga-se, por meio da análise de dados que conduzem a formalizar o referido esquema relacional, o que permite ratificar (ou não) tal relação e estabelecer vínculos entre dados a princípio vistos como não necessariamente interligados.

Ressaltemos que, dos lexemas selecionados para análise em Romero (2016), SECAR, analisado por Kiihl (2016), traz uma dificuldade complementar pelo fato de a sua natureza se aproximar da de um verbo considerado de estado. Desse ponto de vista, SECAR aproxima-se da atribuição de uma qualidade (seco) a um dado suporte, este último devendo ser entendido como o termo sobre o qual recai a referida atribuição e que exibe a qualidade. 0 que nos interessa é examinar o que está envolvido no que se considera, normalmente, uma "atribuição de qualidade" a um suporte. Voltaremos a essas questões mais adiante.

\section{A TOPE e o funcionamento de linguagem}

É na interação - com sujeitos ou com o mundo - que nosso conhecimento linguageiro e linguístico ganha forma. Conforme Culioli (1990), uma vez inseridos em um mundo tomado - e mediado - pela linguagem, construímos noções, representações mentais que organizam as nossas experiências ao longo da vida?

No que se refere ao verbo SECAR, pode-se dizer que, em um dado enunciado, seu emprego, simultaneamente, confere acesso à noção (que notamos < ser SEC >), i.e., a um conjunto de representações evocado pelo verbo e compreendidas como propriedades (ou qualidades) de ordem cognitiva; instancia a noção, posto que a apreende por meio

\footnotetext{
7 Culioli (1990, p. 85) distingue noção de conceito, definindo-a como "representações estruturadas". Tem-se um "conjunto de propriedades que se organizam umas com relação às outras, que são físicas, culturais, antropológicas, e que fazem com que, no fim das contas, um termo não remeta a um sentido, mas a - eu não diria a um campo, posto que um campo já é uma organização de um certo tipo entre termos - [...] um domínio nocional, isto é, a todo um conjunto de virtualidades. [...] A atividade simbólica, por meio da atividade de linguagem, [...] é plástica [...]" (CULIOLI, 1990, p. 86). Em outra passagem, Culioli explica que o nível nocional é "o de nossas representações mentais, relacionadas à nossa atividade cognitiva e afetiva, quer se trate de nossa atividade sensóriomotora no mundo físico ou de nossas elaborações culturais. Na verdade, não existem noções, enquanto feixe de propriedades, que não sejam de ordem físico-cultural." (CULIOLI, 1999a, p. 161).
} 
de uma ancoragem enunciativa não qualquer. Em outras palavras, o acesso ao nível I, nível nocional, de ordem cognitiva, notado por < ser SEC >, se dá por meio do nível II, nível linguístico, do enunciado, que, por sua vez, jamais apreende o nível I em sua totalidade. Há necessariamente um jogo entre o nível I, em que se elabora a noção < ser SEC >, e o nível II, que a instancia (ROMERO, 2017a).

Ao encontro deste posicionamento em relação à atividade cognitiva, Culioli (1997, p. 10) explica que as noções não se encontram previamente estabilizadas, ou remetem a conteúdos localizados no nível I, exatamente por não se lidar com "representações de ordem classificatória, mantidas em estoque, inertes e inalteradas", e, sim, com o que "não cessa de se reorganizar e deformar".

Propomo-nos, a seguir, a redesenhar a relação existente entre o nível I e o nível II, mais precisamente, a formalizar esquemas constitutivos do nível cognitivo; propomo-nos, em suma, sem dúvida de maneira aproximativa, a reconstituir o esquema invariante próprio à atividade de linguagem tal como ele se manifesta por meio dos diferentes enunciados nos quais SECAR se faz presente. Por ser, nessa perspectiva, a invariância própria à forma esquemática que caracteriza o verbo compreendida como relações (entre termos) que se mantêm estáveis sob diferentes transformações, é necessário que haja, com bem dizem Culioli e Normand (2005, p. 21),

[...] um sistema de representação que suporte a generalização, que seja [...] transmissível de observador para observador com um mínimo de perdas, que permita, portanto, a reprodução dos dados e raciocínios, que seja modificável sem que o conjunto se quebre.

\section{Forma esquemática e grupos de funcionamento}

A forma esquemática, ao consistir em um esquema invariante no qual se formula uma representação metalinguística a respeito do funcionamento enunciativo do verbo, deve ser compreendida como o que descreve a regulação de seu enunciar-se. Este conceito constitui o arcabouço de um raciocínio que permite recuperar o papel respectivo do verbo e de seu contexto na variação dos sentidos que, comumente, são associados apenas ao verbo. Espera-se, de uma $\mathrm{FE}$, que descreva o conjunto dos empregos da unidade que caracteriza, sem que, por isso, essa descrição seja "assimilável a algum sentido específico [...]. A FE não é o sentido da palavra, a identidade que constitui não é uma substância autônoma, não é o menor denominador semântico comum dos empregos de uma palavra" (FRANCKEL, 2011, p. 26).

Nas análises realizadas a seguir, trazemos, de início, a forma esquemática proposta como representação do funcionamento de SECAR, para, a partir dela, examinar os parâmetros por ela postos em jogo nos enunciados. Seguem-se a esse exame o que denominamos 
grupos de funcionamento, i.e. configurações segundo as quais, sempre tomando por base a forma esquemática, os parâmetros são mobilizados.

Feitas essas considerações, passemos à forma esquemática do verbo em sua formulação atual: "Dado um suporte $(\mathrm{Y})$ em que se manifesta $(\mathrm{X})$ dotado de liquididade, SECAR conduz à remoção de $(X)^{\prime \prime}$.

Antes de examinarmos como tais parâmetros se configuram nos diferentes enunciados em que SECAR se faz presente, é preciso dizer que o termo liquididade consiste em um metatermo empregado para exprimir o que, em sua ausência, se torna rígido, firme, coeso, sem fluidez. Uma outra importante consideração é que ele indica igualmente a ausência de qualquer forma intrínseca, o que significa que vai se mobilizar um suporte que dê visibilidade - e, por vezes, forma - a essa liquididade.

Os enunciados originam, portanto, ocorrências que mobilizam a noção < ser SEC > de maneiras distintas, por meio dos parâmetros $(X)$ e $(Y)$ envolvidos na relação predicativa instaurada pelo verbo ${ }^{8}$, sem que tais parâmetros correspondam ao que se conhece por argumentos do verbo. Como veremos, $(X)$ e $(Y)$, em um dado enunciado, podem corresponder a um mesmo argumento: o que muda é o modo como esse argumento será delimitado, uma vez que $(X)$ o apreende como dotado de liquididade e $(Y)$ como suporte. Disso decorre que o que denominamos $(X)$ e $(Y)$ pode vir a se referir a termos que não se encontram necessariamente evidenciados ou presentes nos enunciados.

Nas análises a seguir, verificamos, assim, que SECAR solicita um parâmetro (X) liquididade de diferentes ordens, e isso por, justamente, a remoção característica desse verbo se fazer a partir de uma dada liquididade observada. Para cada enunciado, explicamos em que consistem $(X)$, a liquididade, e $(Y)$, seu suporte. Após esse exame preliminar, retomamos o conjunto dos exemplos com intuito de mostrar características específicas aos grupos de funcionamento acima mencionados.

Consideremos, assim, um conjunto de enunciados, analisados sequencialmente.

8 Poder-se-ia dizer que há um terceiro parâmetro, responsável pela passagem de um estado a outro - ou à remoção de $(X)$. Como ilustração, ver nota 7. Não o levamos, contudo, em consideração nas análises, pois nos atemos à questão do suporte $(Y)$ em que se manifesta $(X)$ dotado de liquididade, por consideramos ser este um aspecto central do funcionamento enunciativo do verbo ao qual, pelo que é de nosso conhecimento, pouco se atenta. Centralizamos nossas análises nesses dois parâmetros, sem deixar de mencionar a existência de um elemento que, presente ou não no enunciado, conduziria à remoção de $(X)$. 
2. Outro truque para secar a roupa de forma rápida é colocar a peça molhada, bem dobrada, dentro de uma sacola de plástico e colocá-la no congelador?

O SN a roupa é apreendido pelo verbo sob a ótica de sua composição ${ }^{10}$, i.e. de fibras de tecido nas quais a água se propaga. SECAR diz que as fibras de tecido (roupa), por terem sua água removida, apresentam-se firmes, coesas. A liquididade diz respeito, nesse caso, à água, termo $(X)$, e o suporte, $(Y)$, ao SN a roupa, entendido como fibras nas quais a água se propaga, se espalha.

3. O que ninguém esperava durante a partida, no entanto, é que ela ficasse marcada pela atuação do secador de piso. Acionado no segundo tempo do jogo, ele deu um show à parte. Secou o chão de forma extravagante, usou a cabeça, bateu no chão e encerrou a performance com uma dancinha.

O SN o chão é apreendido como uma superfície, antes umedecida ou molhada, que retorna a seu estado primeiro (chão firme, não escorregadio) pela remoção do líquido nele presente. Nesse caso, (X) é o líquido (na superfície do chão) e (Y) o chão como superfície na qual $(X)$ se propaga.

9 Neste enunciado, o congelador, por exemplo, seria o que efetua a passagem de um estado a outro.

10 Em outros trabalhos (ROMERO; TRAUZZOLA, 2014, entre outros), mostramos como o complemento é delimitado pelos verbos de diferentes maneiras. Assim, se considerarmos "o vaso" com QUEBRAR, em quebrar o vaso, com ROMPER, em romper o vaso, com SECAR, em secar o vaso, têm-se formas de apreensão deveras particulares, que dão a ver o funcionamento enunciativo de cada verbo. Sem entrar nos detalhes das análises, quebrar o vaso faz com o que o SN o vaso seja compreendido ora como um vaso feito de uma matéria quebrável (vidro, porcelana, etc.) cuja unidade se desfaz, dando origem a partes, ora como um vaso feito de outras matérias (aço, por exemplo) cuja unidade igualmente se desfaz (a alça se separa do corpo do vaso, por exemplo), o que significa que se tem igualmente partes do vaso. Com ROMPER, o vaso vai se referir, com muita frequência, a um vaso sanguíneo, e isso porque esse verbo demanda que algo seja contido para poder se enunciar (o vaso sanguíneo contém o sangue: rompê-lo implica ver o sangue sair dos limites impostos pela veia). Isso explica porque o vaso só poderá ser entendido como um objeto mediante contextualizações muito particulares, nas quais ele venha a ser concebido como um recipiente, por exemplo, cheio de terra, que recebe ainda mais terra a ponto de pressioná-lo e fazer o que nele está contido deixar os limites do que o retém. Isso explica ainda porque um SN como o cano, quando empregado com ROMPER, faz obrigatoriamente referência a um cano em uso, em funcionamento. Com SECAR, o vaso dá origem a duas contextualizações possíveis: secar um objeto (e aqui, retoma-se a sua superfície) ou secar um vaso sanguíneo, o que significa levar à extinção do vaso por meio da remoção do líquido nele observado. Esses exemplos, embora não analisados na sequência do artigo, podem ser entendidos quando da explicação dos grupos de funcionamento próprios a SECAR. 
4. O primeiro passo é lavar bastante os grãos, até a água ... SEGUNDO - Seque o arroz na peneira, antes de levá-lo para a panela.

Esse enunciado é interessante por mostrar que o SN o arroz é igualmente apreendido sob a ótica de sua superfície, i.e. como algo passível de ser lavado. Assim, temos (X), que representa o parâmetro liquididade, como a água, e (Y) o arroz, como superfície passível de ser lavada (na qual a água se espalha). No caso de um enunciado como (4a) Aumente o fogo novamente e deixe por mais 1 minuto para "secar" o arroz completamente, o verbo referese à água na qual se prepara o arroz. Notemos que há, portanto, duas contextualizações para secar o arroz: uma na qual se lava o arroz e outra na qual o que se representa é a água que seca por meio da mudança de estado do arroz, que passa a cozido. Neste último caso, $(X)$ é a água e $(Y)$ o arroz, entendido como elemento que contém água.

\section{Tantas despesas inesperadas obrigaram-no a secar a conta bancária.}

Apreende-se o SN a conta bancária por meio de um montante, de uma soma de dinheiro pronta para entrar em circulação ${ }^{11}$. Aqui, a liquididade remete à própria liquidez, ao que está disponível para fluir, circular. SECAR diz que não há mais liquidez em conta. $(X)$ é a conta bancária como o que apresenta liquidez e (Y) a conta bancária, desta vez como um montante, uma dada quantidade. Em outras palavras, $(X)$ atenta para a qualidade de circular do próprio dinheiro e $(Y)$, para a quantidade que se tem.

6. "Meu bebê chorava muito de fome porque meu leite era fraco", "O meu leite secou" ou então "Eu não tinha muito leite para alimentá-lo"...

O SN o meu leite é apreendido como fluxo secretado pelas glândulas mamárias. SECAR diz que as glândulas mamárias deixaram de fazer o leite fluir e encher o peito. (X), o parâmetro liquididade remete ao SN o leite entendido como fluxo e (Y), à quantidade de leite observada (no peito).

7. Palmas tem primeiro dia de racionamento de água. A forte estiagem praticamente secou os mananciais da região.

O SN os mananciais refere-se, neste enunciado, a uma nascente, a um fluxo d'água ininterrupto. SECAR diz que esse fluxo, apreendido pela quantidade de líquido que se tem num dado espaço-tempo, não mais se observa. O termo $(X)$ é os mananciais, como fluxo d'água, e (Y) é também os mananciais, apreendido desta vez como quantidade de líquido observada (na região).

11 Interessante notar que se emprega "salário líquido" para se referir ao salário de que efetivamente se dispõe para consumo. 
8. Esta é uma tentativa de demonstrar que talvez o Pinóquio não tenha nascido um boneco mas que "foram as vivências de maus tratos dentro do seio familiar" que o fizeram secar seu coração até tornar-se madeira.

Nesse enunciado, o termo coração é visto como sede de sentimentos ${ }^{12}$, i.e. como suporte de sentimentos estimulados, animados por algo que lhe é exterior. No caso de SECAR, diferentemente de outros verbos (PARTIR, QUEBRAR ${ }^{13}$ ), exprime-se a impossibilidade de o coração ser suporte de sentimentos, de fazer com que sentimentos dele fluam. (X) é, assim, o fluxo de sentimentos e $(Y)$ seu coração, como o que alimentaria esse fluxo de sentimentos (e não mais o faz).

9. Aos meus tios [...] pelo sorriso e pelas piadas. A distrofia seca seus músculos, mas não seca a vontade e o brilho de viver.

Há, no enunciado, a oração (9a) a distrofia seca os músculos e (9b) não seca a vontade e o brilho de viver. Em (9a), secar os músculos significa perder massa muscular, significa reduzi-la em sua possibilidade de se estender, de se alongar. Logo, SECAR associa-se ao enrijecimento causado pela perda do fluído que permite se estender. Por sua vez, em (9b), a vontade e o brilho de viver são compreendidos, ambos, como uma energia de natureza moral, como disposição para algo. Há, aqui, a representação de um dinamismo físico que recupera o que flui, o que não cessa. Em (9a), (X) é o fluído muscular e (Y) os músculos, em cuja massa se observa o fluído; em (9b), (X) é o fluxo energético e $(\mathrm{Y})$ a vontade e o brilho de viver (de um indivíduo) como o que alimenta o fluxo energético.

10. "Eles (jogadores) estão me secando. Todos eles. Mas deixa, não está adiantando e a hora deles também vai chegar", brincou o treinador durante entrevista coletiva concedida nesta manhã em Porto Alegre.

Nesse último enunciado por nós analisado, faz-se referência à baixa da energia corporal, da vitalidade. Há apreensão de um indivíduo, mais uma vez, do ponto de vista de seu fluxo energético, que poderia ter deixado de se verificar se o SECAR tivesse funcionado. Têmse $(\mathrm{X})$ o fluxo energético e ( $\mathrm{Y}$ ) a disposição, a vitalidade (do sujeito), como o que alimentaria o fluxo energético ${ }^{14}$.

12 Cf. https://www.lexilogos.com/latin/gaffiot.php?q=cor.

13 Ver Romero (2017a).

14 Vale notar que "Eles estão me secando" pode dar origem a contextos nos quais o enunciado é interpretado como alguém que se vê intensamente desejado pelo outro, como mostram os exemplos em que se tem "Ele não para de me secar": "Desde que voltei ao Santuário ele não para de me secar com um olhar devorador" ou "Ela diz que só quer minha amizade porque está ficando, só que não para de me secar. Chega hora que dá até na cara. Se eu for ficar tentando entender 
Os enunciados analisados podem ser agora retomados sob a ótica da relação estabelecida por $(X)$ com seu suporte $(Y)$. É isso que origina diferentes grupos de funcionamento, relacionados, por sua vez, a representações distintas elaboradas pelo verbo em seu enunciar-se.

No grupo I, a liquididade representada por um elemento líquido ou fluído $(X)$ convoca intrinsecamente um termo suporte $(Y)$, que nada mais faz do que propagá-la. Esse termo suporte $(Y)$ localiza $(X)$, de modo que SECAR exprime a retirada ou remoção de $(X)$ de $(Y)$. Pode-se dizer que $(X)$ apresenta-se, por si só, como dotado de uma forma (a forma da matéria que the permite, inclusive, ser entendido como substância) independentemente de (Y), que o localiza. Podemos dizer ainda que, nesse grupo I, SECAR incide sobre termos passíveis de serem encobertos de líquido (lavados, molhados, umedecidos, etc.). O estado primeiro que lhes é próprio é o de ser seco.

São característicos desse grupo os enunciados:

1. No inverno secamos muito os cabelos [...]. Aqui, $(\mathrm{X})$ é a água e $(\mathrm{Y})$, os cabelos, entendido como fibras capilares nas quais a água se propaga, se espalha. SECAR exprime a volta a um estado primeiro seco, que se opõe a molhado: representam-se fibras que tiveram sua água removidas.

2. Outro truque para secar a roupa de forma rápida é colocar a peça molhada, bem dobrada, dentro de uma sacola de plástico e colocá-la no congelador. (X) é a água e (Y), a roupa. (Y) é apreendido sob a ótica de sua composição, i.e. de fibras de tecido nas quais a água se propaga, e SECAR diz a remoção de $(X)$ de $(Y)$.

3. [...] ele deu um show à parte. Secou o chão de forma extravagante, usou a cabeça, bateu no chão e encerrou a performance com uma dancinha. $(X)$ é o líquido e $(Y)$ o chão, como superfície na qual $(X)$ se propaga. SECAR apreende $(Y)$ como uma superfície, antes umedecida ou molhada, que retorna a seu estado primeiro (chão firme) pela remoção de $(X)$.

as mulheres...". Em exemplos como esses, percebe-se que o sujeito representado por "me" (ou qualquer que seja a parte de seu corpo, como "não para de secar as minhas coxas") apresentase como o que alimenta o desejo do outro, como o que lhe preenche uma falta. Embora SECAR, nesses exemplos, não necessariamente remeta a minar o fluxo energético de alguém, constrói-se igualmente uma representação de que o sujeito, com a volúpia ou prazer que o outro imagina com ele ser capaz de obter, é o que preenche uma falta, a falta de outrem (há uma disposição que alimenta um fluxo, tal como em (10), só que feita como que para servir ao outro. Não por acaso, o verbo se aproxima de "cobiçar", "devorar", o que aponta para um "servir à satisfação alheia". 
4. O primeiro passo é lavar bastante os grãos, até a água ... SEGUNDO - Seque o arroz na peneira, antes de levá-lo para a panela. (X) é a água e (Y), o arroz, como superfície passível de ser lavada (na qual a água se espalha). 0 arroz é apreendido como passível de ser lavado, sob a ótica de sua superfície.

No grupo II, a liquididade, representada comumente por um fluxo $(X)$, convoca uma quantidade $(Y)$ apreendida por meio de um termo que lhe confere uma forma circunstancial. Não por acaso, o mesmo SN tende a ser apreendido como $(X)$ e $(Y)$, i.e. por seu caráter fluído e como uma quantidade, quantidade esta que recebe a forma do que dá a vê-la (cf. uma quantidade de leite percebida por meio do peito, por exemplo). SECAR, ao dizer a retirada de $(X)$ de $(Y)$, tende a referir-se ao que se esgota, enrijece, ao que perde a qualidade de liquidez, fluidez. Ao contrário do grupo I, o estado primeiro do qual se parte é o de ser não-seco, como é o caso de um peito em fase de amamentação, do qual se espera que produza leite ${ }^{15}$, ou de uma conta bancária, que tem por função guardar dinheiro.

5. Tantas despesas inesperadas obrigaram-no a secar a conta bancária. $(\mathrm{X})$ e $(\mathrm{Y})$ referemse ao SN a conta bancária, apreendido, respectivamente, como montante passível de circulação, fluidez, e como quantidade (em conta). SECAR diz que não há mais liquidez em conta.

6. [...] "O meu leite secou"... (X) e (Y) referem-se ao SN o meu leite, apreendido respectivamente, como fluxo e como quantidade de líquido que se tem (no peito). SECAR diz que as glândulas mamárias deixaram de fazer o leite fluir e encher o peito.

7. [...] A forte estiagem praticamente secou os mananciais da região. $(X)$ e $(Y)$ referem-se ao SN os mananciais, respectivamente, como fluxo d'água e como quantidade de líquido (na região). SECAR diz que $(X)$, apreendido pela quantidade de líquido que se tem, não mais se observa.

Finalmente, no grupo III, não se trata, como no grupo I, de um suporte $(Y)$ distinto de $(X)$ e que localiza $(X)$, nem, como no grupo II, de um $(X)$ expresso por uma quantidade $(Y)$ manifestada por meio de um termo que dá a vê-la. Tem-se, neste terceiro grupo, uma liquididade $(\mathrm{X})$ entendida como um fluxo que só se verifica porque se auto-alimenta, $(\mathrm{Y})$ consistindo no suporte de um fluxo que não mais existe quando não alimentado.

8. Esta é uma tentativa de demonstrar que talvez o Pinóquio não tenha nascido um boneco mas que "foram as vivências de maus tratos dentro do seio familiar" que o fizeram secar

15 Ressaltemos que se trata, neste caso, de peito considerado em um momento preciso da vida da mulher (o da amamentação), o que explica o estado não-seco como primeiro. Se pensarmos em peito fora desse momento preciso, seria outro seu estado primeiro. 
seu coração até tornar-se madeira. $(X)$ é entendido como um fluxo de sentimentos e $(Y)$, seu coração, como o que alimentaria esse fluxo de sentimentos (e não mais o faz). ( $Y$ ) é, portanto, visto como suporte de sentimentos estimulados, animados por algo que Ihe é exterior. Exprime-se, com SECAR, a impossibilidade de o coração ser suporte de sentimentos, de fazer com que os sentimentos dele fluam.

9. Aos meus tios [...] pelo sorriso e pelas piadas. A distrofia [...] não seca a vontade e o brilho de viver. (X) é o fluxo energético e (Y), a vontade e o brilho de viver (de um indivíduo) como o que alimenta o fluxo energético. Entende-se (Y) como uma energia de natureza moral, como disposição para algo. Há, aqui, a representação de um dinamismo físico que recupera o que flui, o que não cessa.

10. "Eles (jogadores) estão me secando. Todos eles. Mas deixa, não está adiantando e a hora deles também vai chegar", brincou o treinador durante entrevista coletiva concedida nesta manhã em Porto Alegre. (X) é o fluxo energético e $(\mathrm{Y})$, a disposição, a vitalidade (do sujeito), como o que alimentaria o seu fluxo energético. Nesse enunciado, faz-se referência à baixa da energia corporal, da vitalidade. Há apreensão de um indivíduo do ponto de vista de seu fluxo energético, que poderia ter deixado de se verificar se o SECAR tivesse funcionado.

\section{Considerações finais}

Como observado inicialmente, SECAR aproxima-se da atribuição de uma qualidade (seco) a um dado suporte. Ora, a atribuição de tal qualidade não consiste simplesmente em exprimir, por exemplo, que um dado líquido foi removido e que, por isso, algo está seco. $\mathrm{Na}$ verdade, falar em líquido como o que se encontra no fundamento do funcionamento enunciativo verbal não permitiria abarcar as relações que estão por trás do que denominamos liquididade.

Com efeito, se o termo líquido pode facilmente ser associado à representação de uma substância (a água, por exemplo), o termo liquididade remete, sim, ao que pode representar substâncias, mas igualmente ao que apresenta características processuais. É assim que, em muitos dos empregos de SECAR, liquididade diz respeito a fluxo, ao que flui, como se observa em boa parte dos enunciados constitutivos dos grupos II e III.

Por outro lado, é fato que, nos enunciados do grupo I, a liquididade refere-se a SN cuja representação remete a substâncias. SECAR tende, assim, a se opor a MOLHAR, LAVAR, etc., sendo estes empregos, para muitos, os considerados prototípicos.

Interessa notar, antes de mais nada, que a chamada prototipicidade decorre de um mesmo esquema invariante que se encontra na origem dos enunciados que integram 
os outros grupos. O que distingue enunciados do grupo I daqueles dos grupos II e III é, a nosso ver, a característica de $(X)$. Assim, no grupo I, a liquididade é compreendida como o que tem intrinsecamente uma forma, o que Ihe faz aproximar, inclusive, de um ser líquido, de uma substância. Isso faz com que $(Y)$, o suporte, seja um mero localizador, i.e. um termo dotado de uma autonomia em relação a $(X)$, à substância que localiza.

Não é isso que se verifica nos enunciados dos grupos II e III, em que se tem a liquididade apreendida como fluxo, como o que não apresenta, em si, uma forma. No grupo II, a forma lhe é conferida pelo suporte, sempre visto como uma dada quantidade expressa, normalmente, por meio de outro termo. Como já observamos, em (6) O meu leite secou, mais do que dizer que não há leite no peito, é dito que o fluxo $(X)$ que produz uma quantidade de leite $(Y)$ (quantidade esta mostrada pelo peito cheio) foi interrompido. Já no grupo III, não há nenhum tipo de forma (intrínseca, como em I, ou circunstancial, como em II), uma vez que o fluxo (como fluxo energético, fluxo de sentimentos) é visto por meio do que o alimenta.

Talvez seja este o grupo em que o suporte faça efetivamente jus a essa denominação, como o que exibe uma qualidade. Afinal, no grupo I, (Y), termo suporte, localiza (X): em (1) No inverno secamos muito os cabelos [...], a liquididade refere-se à água, entendida como substância, que se localiza em $(Y)$ os cabelos. No grupo II, a liquididade refere-se a um fluxo do qual se origina uma quantidade $(Y)$ a ser especificada por outro termo, não necessariamente presente no enunciado: em (6) "O meu leite secou", trata-se de uma quantidade de leite especificada pela quantidade que se tem no peito. Em suma, no grupo I, o suporte localiza; no grupo II, ele quantifica. No grupo III, ele não tem nenhum papel que não seja o de alimentar, pôr para fluir o que em si é feito para fluir. Isso explicaria as oposições usuais observadas semanticamente: em I, opõe-se SECAR a MOLHAR, LAVAR (UMEDECER), em II, opõe-se SECAR a ENCHER, ao que está cheio, e em III, opõese SECAR a TER VIGOR.

Por fim, se nas mais variadas fontes lexicográficas tem-se SECAR entendido, essencialmente, como o que exprime o ato de tornar algo seco e/ou perder a umidade, cujo sinônimo possível seria ENXUGAR, ou como o que autoriza inúmeros usos "figurados"16 (trazer má sorte ou lançar mau-olhado sobre, reduzir a zero ou fazer esgotar), não é seu papel explicar, como ora tentamos fazer, o que haveria de invariante por trás desta ampla gama de sentidos que lhe são atribuídos.

Foi por meio da análise de como o verbo varia nas mais diferentes construções por ele integradas que buscamos delinear o que se mostra singular e próprio a este verbo, em uma tentativa de formalização do que se passa no nível nocional quando este se encontra posto em uso. Vê-se assim que o interesse maior do estudo é, como bem diz

16 Figurado é a classificação utilizada pelos próprios dicionários. 
De Vogüé (2011, p. 278), o de "aferir, não o que motiva [as formas, os enunciados], mas o que elaboram, [...] não o que seria a causa destas formas, mas o que constitui a sua razão de ser", o de aferir, como observamos em várias passagens, o que caracteriza o seu enunciar-se.

\section{REFERÊNCIAS}

CULIOLI, A. Pour une linguistique de l'énonciation: formalisation et opérations de répérage, t. 2. Paris: Ophrys, 1999a.

CULIOLI, A. Pour une linguistique de l'énonciation: domaine notionnel, t. 3. Paris: Ophrys, 1999b.

CULIOLI, A. A propos de la notion. In: RIVIĖRE, C.; GROUSSIER, M.-L. La notion. Paris: Ophrys, 1997. p. 9-24.

CULIOLI, A. Pour une linguistique de l'énonciation: opérations et représentations, t. 1. Paris: Ophrys, 1990.

CULIOLI, A.; NORMAND, C. Onze rencontres sur le langage et les langues. Paris: Ophrys, 2005.

DE VOGÜÉ, S. Os princípios organizadores da variedade das construções verbais. ReVEL, v. 9, n. 16, p. 276-315, mar. 2011.

FRANCKEL, J.-J. Introdução. In: DE VOGÜÉ, S. et al. Linguagem e Enunciação: representação, referenciação e regulação. Organização de textos e de tradução por Márcia Romero \& Milenne Biasotto-Holmo. São Paulo: Contexto, 2011. p. 15-30.

GARCIA, S. A. Questões de sintaxe sob a ótica enunciativa: contribuições para um ensino reflexivo da categoria verbal. 2014. Dissertação (Mestrado em Ciências) - Escola de Filosofia, Letras e Ciências Humanas, Universidade Federal de São Paulo, São Paulo, 2014.

KIIHL, J. P. Semântica lexical: reflexões sobre o processo de construção da significação e o desenvolvimento de conceitos. 2016. Dissertação (Mestrado em Ciências) - Escola de Filosofia, Letras e Ciências Humanas, Universidade Federal de São Paulo, São Paulo, 2016. 
ROMERO, M. Variation et conservation linguistiques en portugais: identité sémantique des unités verbales et invariance langagière. Signifiances (Signifying), v. 1, n. 3, p. 183-198, $2017 a$.

ROMERO, M. Léxico, invariancia y actividad de lenguaje. In: GARCÍA-MOLINS, A. L.; JIMÉNEZ, D. J. (ed.). Enacción y léxico. Valencia: Tirant Humanidades, 2017b. p. 121-142.

ROMERO, M. Léxico e enunciação: sistematização do funcionamento verbal. Relatório Científico ano II, São Paulo, FAPESP (processo 2013/07572-0), 2016.

ROMERO, M.; TRAUZZOLA, V. S. L. Identidade lexical, funcionamento enunciativo e variação semântica para a Teoria das Operações Enunciativas. Calidoscópio, Rio Grande do Sul, v. 12, n. 2, p. 239-248, mai./ago. 2014. 